\title{
WEAVER, M. (ed.) Transformative learning support models in HE: educating the whole student. London: Facet Press. 2008. 222 pages. ISBN - 978-1-85604644-2. £39.95.
}

When I first saw this title I thought it might contain chapters relevant to me. Although I have moved out of learning support in the library context, I am engaged in research in the Learning \& Teaching Support section of an Academic Registry. I was particularly interested in the subtitle 'Educating the whole student.' When I first skimmed through the book, I felt perhaps it was not as relevant to me in my new role as the title might suggest. However, a somewhat misleading title and lack of relevance to me is not indicative of a lack of relevance to the wider readership. Indeed, I think that it will be of particular interest to those involved in strategic planning such as library managers and student services managers. Since I do not fit into these categories, I hope the readers of this review will forgive my perhaps eccentric approach to the text.

One of the key areas covered by the book, it is claimed, is the "changing profile of learners' which led me to question, 'Who are our learners and how has their profile changed?' From my perspective this would embrace concepts such as widening participation, diversity, first generation students, distance learners, parttime student and students on franchise courses. Platt's chapter deals with widening participation pathways at the University of Manchester whilst a chapter by Marsh discusses capitalising on student diversity and the role of Learner Support Services in the Bradford student experience. Oddly, however, these two chapters were in different sections of the book and I could not quite understand why Platt's contribution had been consigned to the end of the second part of the book rather than following Marsh's piece in the first part, which I feel would have been more logical.

Cohen and Harvey's chapter discusses 'next generation' learning spaces to fit the changing profile of learners and the increasingly diverse student population. They include descriptions of some physical learning spaces and I feel these descriptions could have been enhanced by photographs or diagrams. There is a dearth of illustrative material in the text which is quite dense and demanding and could have been broken up by the inclusion of more charts, tables and other representations. When I refer to density and demand, this is not an implied criticism. It is inevitable, when a volume brings together a collection of shared thoughts and perceptions from a variety of worthy sources in a variety of writing styles that the reader is challenged. The challenging of some of our own thoughts and perceptions is, indeed, one of the strengths of the book and the editor, Weaver, is to be congratulated on gathering together these thought-provoking chapters.

The 'whole student' approach, involving supporting students socially, physically and academically is commendable. As Roberts and Stewart, in their very readable chapter, quote McInnes et al (2000) on how personal and emotional issues can have direct consequences for successful study. A New Zealand case study is offered by these authors and this is most welcome, as is Brophy's chapter giving a European perspective of the integration of physical and virtual environments to 
support higher education learners and Brown and Porterfield's chapter focussing on increasing student affairs' sphere of influence. The inclusion of more international case studies would have been appreciated and would have rendered the text more relevant to a wider, international audience. The publisher's blurb does talk about interfacing with the global skills agenda and perhaps gives the impression that the book takes a more international perspective than it in fact does.

The book makes a strong argument against the 'silo' mentality and for a collaborative environment of shared goals, learning partnerships and cross-service tasks. This is commendable and shows a customer-orientated perspective typified by LLS and other University support staff.

As I researcher, I found my appetite whetted by part 3's promise that we might learn 'from each other using research-informed approaches.' Whilst reading successive chapters by Martin who describes research project in learners' use of technologies at Edge Hill and Atkins who lists some examples of practical pedagogical research and practitioner enquiry, I felt that I wanted to know more about these projects than I was told. I guess the onus is on me to follow these up since I am sure that the word limit imposed on authors made it impossible to include more details. Weaver and Levy's concluding chapter redressed what I perceived to be an imbalance and delivered what it promised by highlighting the 'transforming potential and outcomes that arise when embedded models of critical inquiry into learning and its support are employed and acted upon'. I suspect this chapter and the book as a whole will inspire its readers to move from 'artful doing' to 'artful knowing'.

\section{Pat Gannon-Leary}

\section{University of Northumbria}

\section{pat.gannon-leary@northumbria.ac.uk}

